\title{
Alinhando governança corporativa e gestão: descrição e análise do modelo do Banco Central do Brasil ${ }^{1}$
}

\section{Rosalvo Ermes Streit}

Banco Central do Brasil (BC) e Universidade Católica de Brasília (UCB), Brasília, DF - Brasil

\section{Fernando de Abreu Faria}

Banco Central do Brasil (BC), Brasília, DF-Brasil

A governança se tornou um tópico de interesse nas organizações públicas, porém, o tema é relativamente novo nos bancos centrais. Assim, para promover uma melhor compreensão sobre o tema, este artigo apresenta um modelo que evidencia a forma como a governança corporativa e a gestão se relacionam no Banco Central do Brasil (BCB). Em sua essência, o conceito de governança corporativa diz respeito ao sistema pelo qual as organizações são dirigidas e controladas. O modelo foi desenvolvido por meio de uma pesquisa aplicada e organizado em quatro etapas: planejamento, pesquisa bibliográfica e documental, pesquisa participante para construção do modelo e elaboração do relatório final. A etapa da pesquisa participante envolveu servidores do BCB que atuam nos temas de governança e gestão da organização. Para a representação do conhecimento, utilizou-se abordagem baseada em aspectos semânticos. O modelo resultante deste trabalho foi empregado para descrever e comunicar os processos de governança e gestão da organização. A sua importância reside na capacidade de demonstrar o alinhamento entre a governança e a gestão do $\mathrm{BCB}$, o processo decisório, as relações das principais partes interessadas, bem como a interdependência dos instrumentos de gestão administrados por diferentes departamentos na organização, permitindo entender a complexidade do ambiente organizacional mediante a identificação dos seus elementos e da sua semântica.

Palavras-chave: governança corporativa, bancos centrais, governança e gestão

\footnotetext{
${ }^{1}$ As opiniões expressas neste trabalho são exclusivamente dos autores e não refletem, necessariamente, a visão do Banco Central do Brasil.
}

DOI: $10.21874 /$ rsp.v71i2. 3185| ISSN: 0034-9240 | E- ISSN: 2357-8017

[Artigo recebido em 27 de dezembro de 2017 e aceito em 5 de março de 2020.] 


\section{Alineando la gobernanza corporativa y la gestión: descripción y análisis del modelo del Banco Central de Brasil}

La gobernanza se ha convertido en un tema de interés en las organizaciones públicas, sin embargo el tema es relativamente nuevo en los bancos centrales. Así, para promover una mejor comprensión del tema en estas organizaciones, este artículo presenta un modelo que muestra cómo la gobernanza corporativa y la gestión están relacionadas en el Banco Central de Brasil (BCB). En su núcleo, el concepto de gobernanza corporativa se refiere al sistema por el cual las organizaciones son administradas y controladas. El modelo se desarrolló a través de una investigación aplicada y se organizó en cuatro etapas: planificación, investigación bibliográfica y documental, investigación participante para construir el modelo y preparar el informe final. La etapa de investigación participante involucró a los empleados de BCB que trabajan en los asuntos de gobernanza y gestión de la organización. Se utilizó un enfoque basado en aspectos semánticos para representar el conocimiento. El modelo resultante de este trabajo se usó para describir y comunicar los procesos de gobernanza y gestión de la organización. Su importancia radica en la capacidad de demostrar el alineamiento entre la gobernanza y la gestión del BCB, los procesos de toma de decisiones, la relación de los principales actores, así como la interdependencia de los instrumentos de gestión administrados por los diferentes departamentos de la organización, lo que permite comprender la complejidad del ambiente organizacional mediante la identificación de sus elementos y su semántica.

Palabras clave: gobernanza corporativa, bancos centrales, modelo de gobernanza y gestión

\section{Aligning corporate governance and management: description and analysis of the Banco Central do Brazil model}

Governance has become a topic of interest in public organizations, but the theme is relatively new among central banks. Therefore, to promote a better understanding of the subject in these organizations, this article presents a model that shows how corporate governance and management are related in the Central Bank of Brazil (BCB). At its core, the concept of corporate governance refers to the system by which organizations are run and controlled. The model was developed through an applied research and organized in four stages: planning, bibliographic and documentary research, participatory research to build the model and prepare the final report. The participatory research stage involved BCB employees who work on the organization's governance and management issues. An approach based on semantic aspects was used to represent the knowledge. The model resulting from this work was used to describe and communicate the governance and management processes of the organization. Its importance lies in its ability to demonstrate the alignment between BCB governance and management, the decision-making processes, the relationship of key stakeholders, as well as the interdependence of management tools administered by different departments in the organization, making it possible to understand the complexity of the organizational environment through the identification of its elements and semantics.

Keywords: corporate governance, central banks, governance and management 


\section{Introdução}

A governança se tornou um tópico de debate e interesse internacional, não apenas nos órgãos governamentais, como também no setor corporativo e no meio acadêmico. Historicamente observa-se que a perspectiva da governança é extremamente relevante para o setor financeiro. As crises financeiras na Ásia, na Rússia e em outros países atestaram a importância da governança para a estabilidade econômico-financeira. Embora as circunstâncias fossem diferentes, os países em crise tinham estruturas de governança distorcidas que conduziram à tomada de decisões econômicas ineficientes (WITHERELL, 2000).

Da mesma forma, a recente crise das hipotecas subprime (subprime financial crisis) evidenciou diversos problemas, sendo que os mecanismos inadequados de governança corporativa dos bancos têm sido apontados como os principais fatores que contribuíram para as adversidades (MARCINKOWSKA, 2012). Observa-se que problemas nos mecanismos de governança podem criar condições de risco, que levam as instituições financeiras a assumir posições excessivas de riscos, deixando-as vulneráveis, por exemplo.

A crise das hipotecas subprime provocou debate sobre os objetivos e a estrutura de governança de bancos centrais (KOETTER et al., 2012). O tema governança corporativa é relativamente novo nos bancos centrais. Diversos autores e instituições supragovernamentais (Bank for International Settlements - BIS -, Fundo Monetário Internacional - FMI - e outros) têm produzido e publicado inúmeros estudos sobre o assunto, fazendo com que os bancos centrais evoluam em direção à adoção e difusão das melhores práticas de governança.

Um aspecto bastante citado na literatura quando o assunto se refere à importância do estudo e pesquisa da governança corporativa diz respeito à sua relação com o desempenho das organizações. Conforme Lynn (1997), a importância da pesquisa sobre governança está no seu poder de ligar o desempenho a suas causas. Por essa razão, um importante objetivo da pesquisa nessa área é a identificação da influência dos vários elementos que compõem a ação coletiva no desempenho governamental (LYNN et al., 2001). 
A governança corporativa dos bancos centrais, devido a suas atribuições específicas, difere da governança de outras organizações. As atribuições dos bancos centrais usualmente estão associadas à missão de assegurar a estabilidade do poder de compra da moeda nacional, bem como promover a eficiência e o desenvolvimento do sistema financeiro de um país (BRASIL, 2016).

Hilbers e Dalton (1999) enfatizam a importância dos controles internos e da auditoria interna para o aprimoramento da governança corporativa dos órgãos de regulação. Os sistemas de controles internos podem auxiliar os bancos centrais a alcançar os seus objetivos. Segundo os autores, esses sistemas são planejados para fornecer uma razoável garantia para a realização dos objetivos A auditoria interna é o processo que controla os sistemas de controle, por intermédio de revisões regulares das operações e pela emissão de pareceres que podem reduzir os riscos dos bancos centrais.

Assim, para promover uma melhor compreensão sobre o tema, o objetivo deste estudo é promover a compreensão e, consequentemente, a adoção de boas práticas de governança corporativa e de gestão nas organizações. Para isso, este trabalho apresenta um modelo que evidencia a forma como a governança interna e a gestão se relacionam, e pode ser utilizado como uma ferramenta para o entendimento das regras de governança e para o fortalecimento da gestão institucional. O modelo é o do Banco Central do Brasil (BCB) e aborda aspectos semânticos como alternativa às estruturas de governança existentes.

\section{Governança corporativa em bancos centrais}

O tema governança corporativa é relativamente novo nos bancos centrais. A maior parte deles passou a considerar e implantar as suas práticas nos últimos dez anos. Segundo o Bank for International Settlements (BIS) (2009), uma das tarefas mais difíceis de organização de um banco central é a definição da sua estrutura de governança, de modo que permita o alcance dos seus objetivos e a garantia de responsabilidade por suas ações. Em sua essência, o conceito de governança corporativa diz respeito ao sistema pelo qual as organizações são dirigidas e controladas (CADBURY, 1992). 
Segundo Amtenbrink (2005), a governança em um banco central pode ser definida por três pilares, que juntos formam a base do seu quadro jurídico: independência, accountability $^{2}$ e transparência. Esses três pilares não constroem instantaneamente a confiança da sociedade na instituição, mas são considerados elementos essenciais para que se obtenha a inserção social e a credibilidade do banco central ao longo do tempo.

Para Oritani (2010), a estrutura de governança em bancos centrais tem dois aspectos: governança corporativa e governança pública. No primeiro, são considerados os elementos de governança usualmente utilizados como comitês, accountability, transparência. No segundo, deve ser estabelecida a relação do banco central (o agente) com a sociedade (o principal) e com o representante eleito pelo principal, seja o chefe do Poder Executivo ou do Poder Legislativo. É uma relação mais complexa e que necessita de regras claras de accountability (FARIA; STREIT, 2016).

De acordo com Mendzela (2009), para compreender a governança corporativa nessas instituições é importante distinguir a governança de políticas da governança institucional. A primeira refere-se aos processos de governança aplicados sobre as definições das políticas que estão a cargo de um banco central, como, por exemplo, a política monetária, cambial e de estabilidade financeira. A última refere-se às políticas que são aplicadas para a gestão da organização.

Essa distinção de governança nos bancos centrais também é compartilhada por Koch (2007), que a separa em governança externa e governança interna. O desafio da governança externa lida principalmente com o papel e a função do banco central na sociedade propriamente dita, e é, portanto, localizada firmemente no domínio da economia política de cada país. O desafio da governança interna diz respeito à forma como o banco central conduz seus negócios, dentro dos parâmetros gerais estabelecidos pelos arranjos de governança externos. Para Khan (2016), a governança interna incorpora todos os arranjos internos da organização, como: (i) a estrutura; (ii) o processo de tomada de decisão; (iii) o gerenciamento de riscos; (iv) os mecanismos de controle; e (v) a auditoria interna. Ou seja, todos os arranjos que influenciam a tomada de decisão do banco central.

\footnotetext{
${ }^{2} \mathrm{O}$ termo accountability é empregado no trabalho sem tradução, pois não há uma palavra na língua portuguesa que sintetize o seu significado. Segundo o ECB (2002) e Eijffinger e Geraats (2006), accountability relaciona-se à prestação de contas e também à responsabilização dos atos.
} 
Cabe destacar que o BIS (2009) classifica as decisões dos bancos centrais em três categorias: (i) formulação e implantação de políticas (conselho de políticas); (ii) gestão e administração (conselho de gestão); e (iii) supervisão do desempenho da instituição (conselho ou comitê de supervisão).

O modelo de Lybek e Morris (2004), apresentado na Figura 1, sintetiza quatro grandes fatores que, segundo os autores, devem ser considerados em uma estrutura de governança consistente de bancos centrais. São eles: (i) fatores específicos do país; (ii) objetivos, autonomia e autoridade; (iii) accountability; e (iv) estrutura dos corpos de governança.

\section{Figura 1 | Fatores de estrutura de governança para bancos centrais}

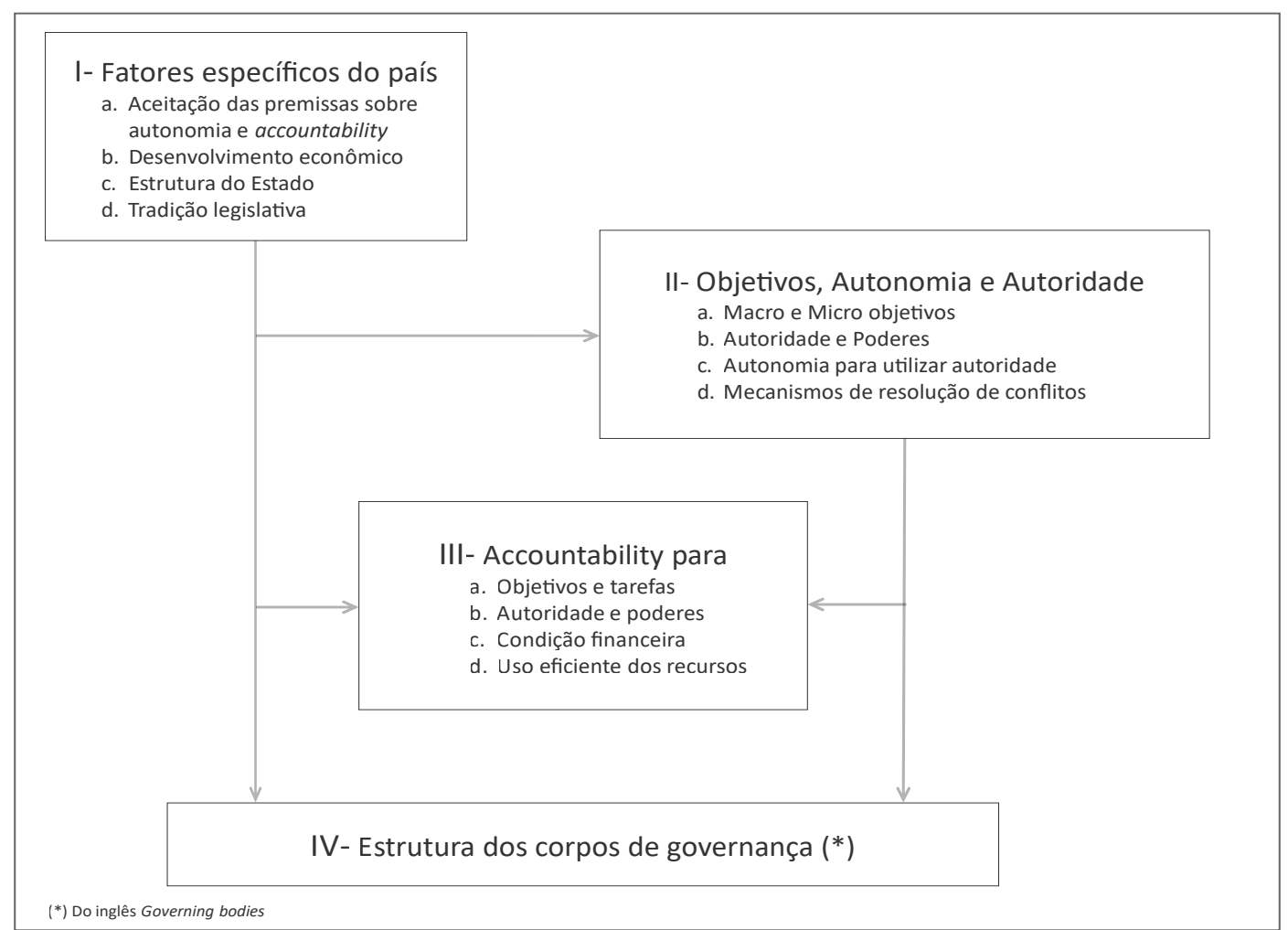

Fonte: adaptado de Lybek e Morris (2004).

Os bancos centrais podem contribuir para os dois primeiros fatores (Fatores específicos do país e Objetivos, autonomia e autoridade) por meio de sua relação com o 
Congresso e com a sociedade, de forma a influenciar os políticos e os cidadãos sobre a importância da sua missão. Esses fatores referem-se à governança externa e não dependem exclusivamente da ação do banco central. Os bancos centrais também podem atuar fortemente nos outros dois fatores (Accountability e Estrutura dos corpos de governança), relativos à governança interna, adotando práticas de governança internacionalmente aceitas, bem como aprimorando a composição e o funcionamento dos seus comitês. A utilização de comitês é prática comum em bancos centrais, e diversos autores e organismos internacionais já abordaram o tema em inúmeras publicações (SCHIFFMAN, 2004; BERGER; NitSCH; LYBEK, 2006; SiBERT, 2006; CROWE; MEADE, 2007).

As práticas e regras de governança propiciam, dentre outros benefícios, que a gestão seja feita com foco nas prioridades definidas pela organização e que os tomadores de decisão tenham suas ações avalizadas por um arcabouço institucional formalmente constituído. Contudo, conforme Lynn et al. (2001), o conceito de governança no setor público é usualmente mais complexo do que no setor privado. No setor público, os objetivos e os resultados das transações são menos visíveis e quantificáveis, o poder da direção e controle é mais disperso e os objetivos dos atores são mais variados e muitas vezes conflitantes.

Assim, para o entendimento inequívoco das regras de governança e, consequentemente, a sua aplicação para o efetivo fortalecimento da gestão institucional, é importante que fique evidente para a organização a forma como a governança e a gestão organizacional se relacionam.

\section{A importância de um modelo de governança e gestão}

A literatura mostra que a diferença entre governança e gestão ainda não está clara e necessita de melhor elucidação (OFFE, 2009; ROTH et al., 2012). Para entender as diferentes áreas de foco da governança e da gestão de uma organização, bem como os seus relacionamentos e interdependências, é importante uma visão abrangente que contemple os seus principais elementos e objetos de gestão. Nesse sentido, entende-se que modelos podem ser empregados para reduzir a complexidade do tema, capturando os aspectos relevantes para a sua caracterização e representação. 
Ainda em relação à diferença entre os conceitos de governança e gestão, apresentase a visão de Peterson (2004) e de Van Grembergen e Haes (2009), na área de TI, e de Roth et al. (2012), que trata das diferenças e inter-relações entre esses conceitos no âmbito de redes interorganizacionais. Para Peterson (2004), a gestão de TI é mais relacionada ao presente e aos assuntos internos, enquanto a governança de TI vai além dessas questões, também tratando com assuntos externos e outros associados ao futuro. Ou seja, com base nesses autores, a gestão refere-se à tomada de decisões em nível tático e operacional, ao passo que a governança refere-se à criação de um contexto no qual os outros podem gerenciar efetivamente. Roth et al. (2012, p. 112), por sua vez, argumentam que a "governança consiste na definição de regras, critérios para a tomada de decisão, responsabilidades e limites de autonomia e ação dos participantes [...] O seu papel não é o de gerir, mas de delimitar a gestão". Neste caso, segundo os autores, os gestores têm liberdade para utilizar os seus conhecimentos e habilidades, adequando práticas para atender às estratégias organizacionais.

Há uma variedade de abordagens de modelos na área da governança e da gestão, para diferentes tipos de organizações. No setor público brasileiro, cabe destacar a publicação recente do Tribunal de Contas da União (TCU, 2014) de um referencial básico aplicável a órgãos e entidades da administração pública. O TCU organiza os componentes do seu modelo, práticas e itens de controle sob a perspectiva de três mecanismos de governança: (i) liderança, que se refere ao conjunto de práticas de natureza humana ou comportamental; (ii) estratégia, que é necessária à boa governança; e (iii) controle, que avalia e trata os riscos da execução dos processos organizacionais. Esse modelo tornou-se referência no setor público, pois introduziu marcos relevantes para o aprimoramento da governança corporativa de organizações públicas. Contudo, há críticas em torno de sua abordagem prescritiva-formal, que carece de validação científica e de apoio em práticas da administração pública (CAVALCANTE; PIRES, 2018).

Conforme a Deloitte (2013), o entendimento e as possibilidades em relação à governança mudaram ao longo dos últimos anos, aumentando as expectativas das 
partes interessadas em relação aos conselhos de administração ${ }^{3}$, em termos da sua responsabilidade e envolvimento no processo de governança das organizações.

Enquanto o conselho de administração é responsável pela supervisão do processo de governança, a gestão é responsável por implementar as políticas e procedimentos através dos quais a governança ocorre dentro da organização. O conselho de administração é responsável pela compreensão - e pelo assessoramento dos gestores - dos processos pelos quais a governança ocorre dentro da organização, bem como é responsável pelos resultados desses processos. A gestão é responsável pelos processos de governança e seu funcionamento, e pelos seus resultados. (DeloItTE, 2013, p.1).

Um modelo de governança para essa compreensão é fundamental, pois apoia o conselho e os gestores na consecução de suas funções para a efetividade da governança. Os modelos de gestão, por sua vez, procuram representar os elementos relevantes de gestão e as suas relações com os diversos objetivos organizacionais. Ou seja, preocupam-se com as operações diárias no contexto das estratégias, políticas, processos e procedimentos estabelecidos pela alta administração.

Apesar da grande variedade de modelos de governança e de gestão, não é comum a existência de propostas de modelos que contemplem ambas as dimensões. Enquanto a governança se preocupa com o direcionamento, a gestão se preocupa com a execução. A vantagem de um modelo de governança e de gestão relaciona-se à sua capacidade de explicitar as relações entre ambos os domínios, em função dos modelos reduzirem a complexidade da realidade sob análise a um nível adequado para a sua compreensão. Observa-se que algumas organizações demonstram dificuldade em internalizar a compreensão da diferença entre os conceitos de governança e de gestão. Além disso, a adoção de um modelo único pode promover a realização de estudos e análises sobre os efeitos da governança e da gestão no desempenho organizacional.

Para a construção de modelos que representem as relações entre os elementos de governança e de gestão de uma organização, entende-se que as redes semânticas e as ontologias são os mais adequados. A seguir, essa abordagem é analisada em detalhes.

\footnotetext{
${ }^{3}$ No caso do BCB, a Diretoria Colegiada trabalha com a estrutura de um colegiado. É composta por oito diretores e um presidente, todos eles com direito a voto nos comitês que atuam (Comitê de Política Monetária - COPOM; Comitê de Estabilidade Financeira - COMEF; e Comitê de Governança, Riscos e Controles - GRC). Os seus membros participam de processos decisórios de políticas e de gestão.
} 


\section{A representação do conhecimento com o uso de redes semânticas e ontologias}

Observa-se que as redes semânticas, ontologias e os mapas conceituais, que são técnicas de organização e representação do conhecimento, têm sido empregadas para lidar com a compreensão da complexidade de uma determinada realidade e com os conceitos presentes em um domínio. Enquanto as ontologias definem vocabulários para pesquisadores que necessitam compartilhar informações em algum domínio ou assunto (NOY; MCGUINESS, 2001), as redes semânticas possibilitam representar qualquer tipo de conhecimento que pode ser descrito na linguagem natural (LEHMANn, 1992), para a sua visualização e apresentação. As representações semânticas de conhecimento conhecidas como redes semânticas e mapas do conhecimento também estão alinhadas com a definição de mapas conceituais (ALBERT; STEINER, 2005). Ainda, segundo Canãs e Novak (2009), os mapas conceituais são redes semânticas com representações menos rígidas e formais, que não necessitam serem interpretadas por computadores.

É possível verificar diversas definições de ontologia na literatura, sendo que, segundo Guarino (1997), uma das mais citadas é a de Gruber (1995, p. 1): “Ontologia é uma especificação explícita de uma conceituação". Nessa definição, a conceituação pode ser entendida como uma "interpretação estruturada de uma parte do mundo que as pessoas utilizam para pensar e comunicar sobre o mundo" (BORST, 1997, p. 12). Conforme Haidegger et al. (2013), as ontologias atuam como um corpo de conhecimento baseado em um vocabulário, que é utilizado para descrever um domínio.

Medina Nieto (2003) identificou certos aspectos essenciais das ontologias, a partir de algumas definições existentes: (i) as ontologias são utilizadas para descrever um domínio específico; (ii) os termos e relações são claramente definidos nesse domínio; (iii) utiliza-se um mecanismo para organizar os termos (usualmente utiliza-se uma estrutura hierárquica); e (iv) há um acordo entre os usuários da ontologia para que o significado dos termos seja empregado de forma consistente. Segundo a autora,

As ontologias podem ser usadas para suportar uma grande variedade de tarefas em diversas áreas de pesquisa, como representação do conhecimento, processamento de linguagem natural, recuperação de informações, bancos de dados, gestão do conhecimento, integração de banco de dados online, bibliotecas digitais, sistemas de 
informação geográfica, recuperação visual de informações ou sistemas multiagentes (Medina Nieto, 2003, p. 4).

As redes semânticas, por sua vez, são formas gráficas para a representação do conhecimento, que utilizam nós e arcos interconectados. Conforme Lehmann (1992), ideias, eventos, situações ou objetos quase sempre têm a composição de uma estrutura e, assim, podem ser representados em uma rede semântica, ou seja, por uma estrutura correspondente a nodos (desenhos de círculos ou caixas), representando unidades conceituais, e ligações (desenhos de setas entre os nodos), representando as relações entre essas unidades. Essa representação gráfica declarativa é comum a todas as redes semânticas e pode ser empregada para representar conhecimento ou para apoiar sistemas automatizados no raciocínio do conhecimento representado (SoWA, 1992).

As redes semânticas têm sido utilizadas na Filosofia, Psicologia e Linguística, mas as primeiras implementações computacionais foram desenvolvidas para a área da inteligência artificial (SoWA, 1992). Elas possuem diversas vantagens como ferramentas para a representação do conhecimento, pois são mais fáceis de compreender do que as formas lineares (HARTLEY; BARNDEN, 1997). Na área da computação, observa-se a popularidade das redes semânticas nas aplicações de processamento de linguagem natural, bem como nos estudos relacionados à web semântica (GUNS, 2013).

Segundo Duarte (2011), os pesquisadores que estudam ontologias têm devotado atenção aos diversos elementos organizacionais e às suas relações, objetivando entender a complexidade do ambiente organizacional mediante a identificação dos seus elementos e da sua semântica. Entretanto, observa-se a existência de poucos trabalhos na literatura que abordam a representação do conhecimento de governança e gestão com ontologias, redes semânticas ou mapas conceituais. Em geral, os estudos identificados envolvem o desenvolvimento de modelos semânticos e de vocabulários nessa área. Em função da popularidade das redes semânticas no campo da tecnologia da informação, os principais exemplos apresentados nesta seção provêm dessa área.

Moreira et al. (2008), por exemplo, apresentam uma estrutura para a governança da segurança da informação, desenvolvida para motivar os gestores a empregar melhores práticas de gestão de segurança em todos os níveis da organização. Para facilitar a correlação dos diferentes incidentes de segurança e vulnerabilidades de várias fontes, 
bem como a gestão da segurança da informação e conhecimento, os autores utilizam duas ontologias que definem um vocabulário único de conceitos e relacionamentos: (i) ontologia de incidentes de seguranças; e (ii) ontologia de vulnerabilidade. As ontologias ajudam a lidar com as dificuldades relacionadas à quantidade, diversidade e a falta de semânticas na área da governança e da gestão da segurança da informação. Adams (2008) descreve o desenvolvimento de uma ontologia de governança da inovação para que os pesquisadores e formuladores de políticas compreendam os principais conceitos desse domínio complexo de conhecimento e a perspectiva transdisciplinar dessa área. Brandas (2012) elaborou um modelo de representação formal do conhecimento sobre os códigos e princípios de governança corporativa, para analisar a efetividade e a eficiência dos mecanismos de governança e contribuir na otimização dos processos de governança pelas empresas. Souza Neto e Ferreira Neto (2013) desenvolveram um metamodelo ontológico para representar as estruturas conceituais do Cobit 4.1 de governança de $\mathrm{TI}$ para a avaliação desse modelo. O estudo de Brandis et al. (2014), por sua vez, apresenta um modelo de governança de serviços de TI na nuvem, com foco em aspectos semânticos para viabilizar e facilitar a aplicação desse modelo.

Apesar das ontologias fornecerem descrições conceituais que são frequentemente utilizadas por computadores para pesquisa, troca de informações e processamento semântico, o desenvolvimento de ontologias em áreas específicas depende de especialistas, com conhecimento e experiência em determinados domínios, e de um processo longo e trabalhoso de análise, síntese, abstração e revisão (CHOU et al., 2012). Segundo Salem e Alfonse (2008), que estudaram as diferenças entre as redes semânticas e ontologias para a representação de conhecimento na área médica, as ontologias são técnicas mais robustas para a representação do conhecimento e, deste modo, mais adequadas para o desenvolvimento de sistemas baseados em conhecimento.

Hartley e Barnden (1997) ressaltam que a capacidade das redes semânticas de representação de estruturas de conhecimento deve ser mais bem explorada. Embora o seu aspecto visual seja reconhecido, este não tem sido estudado de forma mais ampla. De acordo com Salem e Alfonse (2008), as redes semânticas são mais fáceis de visualizar e os conhecimentos relacionados podem ser agrupados de forma mais simples. Assim, neste trabalho, a técnica das redes semânticas foi escolhida para descrever o modelo 
de governança e gestão do $\mathrm{BCB}$, na forma de conceitos e relacionamentos entre esses conceitos (mapa conceitual) para comunicar o entendimento das principais relações entre os distintos objetos de gestão e de governança da organização.

\section{Metodologia}

Quanto à natureza, esta pesquisa é classificada como aplicada; quanto à forma de abordagem, é qualitativa; e quanto aos fins, é descritiva. É aplicada porque objetiva promover a compreensão e a adoção de boas práticas de governança corporativa e de gestão. É qualitativa pelo foco no estudo do fenômeno e do seu significado. É descritiva porque busca analisar, observar e registrar aspectos que envolvem fatos ou fenômenos relacionados à governança e gestão do $\mathrm{BCB}$, sem manipulá-los. De acordo com Sampieri et al. (2006), a pesquisa descritiva busca especificar propriedades e características importantes de qualquer fenômeno que se analise.

Quanto aos procedimentos técnicos, pode ser classificada como bibliográfica, porque foi elaborada a partir de material já publicado, como artigos científicos, livros e outros documentos disponibilizados no sítio do BCB; é documental por trabalhar com documentos internos do BCB que têm valor científico para o objetivo proposto no estudo; e, também, adotou como estratégia a pesquisa participante, pois houve envolvimento dos pesquisadores e pesquisados no processo de pesquisa (GIL, 2008).

O estudo foi organizado em quatro etapas: planejamento, pesquisa bibliográfica e documental, pesquisa participante para construção do modelo e elaboração do relatório final.

$\mathrm{Na}$ etapa de planejamento foi definido o escopo da pesquisa e foram delineadas as etapas necessárias à sua execução. Na fase de pesquisa bibliográfica foram estudados artigos acadêmicos e livros relacionados ao tema proposto. Na pesquisa documental foram coletados e analisados documentos internos da organização como, por exemplo, o regimento interno, votos da diretoria e manuais técnicos. 
Este estudo iniciou-se em 2013, quando o TCU solicitou aos dirigentes máximos de suas áreas jurisdicionadas que o relatório de gestão referente ao exercício de 2012 evidenciasse as estruturas de governança das organizações, explicitando as instâncias dessas estruturas. Assim, para o atendimento dessa demanda, foi desenvolvido um modelo de governança, com base na estrutura de representação utilizada pelo Instituto Brasileiro de Governança Corporativa (IBGC, 2009), que foi sendo aprimorado ao longo dos anos. Desse modo, surgiu a ideia de estender o modelo para a incorporação de aspectos relevantes da gestão da instituição.

A etapa da pesquisa participante envolveu servidores do $B C B$, principalmente aqueles lotados no Departamento de Planejamento, Orçamento e Gestão (Depog). Vale ressaltar que o principal desafio para o desenvolvimento do modelo de governança e gestão descrito neste estudo foi a identificação de aspectos relevantes a serem incorporados e a definição da forma para a sua representação. Nesse aspecto, foi importante a participação e contribuição dos participantes nas oficinas de trabalho em que foram discutidas a governança e a gestão no $\mathrm{BCB}$, que contribuíram para o desenvolvimento do modelo proposto com sua experiência e conhecimento nesse tema. Foram realizados seis encontros, com a participação média de cinco servidores. Em cada encontro discutiram-se os principais elementos de governança e gestão e suas relações. Cada encontro iniciava com um resumo sucinto das discussões anteriores e apresentação parcial do modelo.

Nas reuniões, foram utilizados conceitos recuperados da literatura sobre governança e gestão do referencial básico de governança do TCU (TRIBUNAL DE CONTAS DA UNIÃO, 2014) e dos documentos internos para representar a estrutura de governança e gestão do BCB. Como se pode verificar na próxima seção, no modelo estão presentes os atores da governança interna e externa do banco, além dos principais elementos de gestão.

\section{O modelo de governança e gestão do Banco Central do Brasil}

Como resultado da observação e da consulta a documentos da organização, o primeiro passo para a elaboração do modelo de governança e gestão foi o desenvolvimento de uma representação sucinta, com a descrição dos principais componentes da sua estrutura. 
Esse modelo baseia-se na estrutura de representação utilizada pelo Instituto Brasileiro de Governança Corporativa (IBGC, 2009) para o sistema de governança das organizações. O resultado da primeira versão do modelo foi publicado no Relatório de Gestão do $B C B$, no 1ㅇ semestre de 2013, sendo que uma versão mais recente desse modelo, reproduzida na Figura 2, pode ser verificada no sítio do Banco Central do Brasil (BCB, 2016).

\section{Figura 2 | Estrutura de governança do Banco Central do Brasil}

Governança

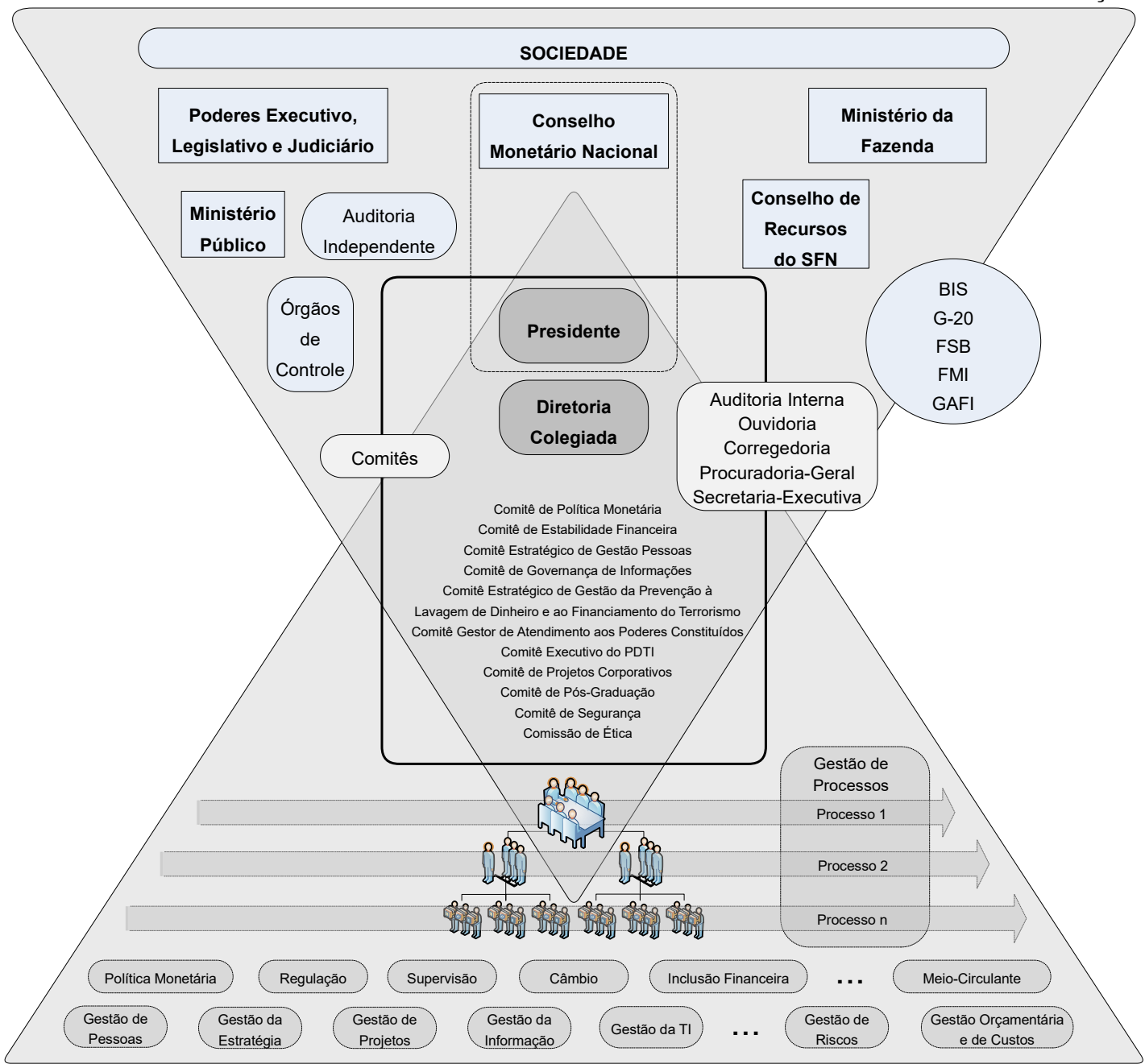

\section{Gestão}


Conforme se observa na Figura 2, o triângulo invertido do modelo (BCB, 2016):

[...] evidencia os principais atores externos que zelam pela governança da organização (sociedade, CMN, Ministério da Fazenda ${ }^{4}$, Ministério Público, CRSFN, Poderes Executivo, Legislativo e Judiciário, órgãos de controle e auditoria independente). No triângulo não invertido da estrutura, por sua vez, são tratadas as questões de gestão. Desse modo, controle e gestão estão separados. Os elementos presentes no retângulo central (Presidente, Diretoria Colegiada, Comitês, Auditoria Interna, Ouvidoria, Corregedoria, Procuradoria-Geral e Secretaria-Executiva) asseguram o elo entre os atores externos e a gestão da organização (BANCO CENTRAL Do BRASIL, 2016, p. 80).

Os atores que compõem o modelo foram categorizados em atores externos, organismos internacionais e atores internos. Também, cabe ressaltar que a base do triângulo da gestão (triângulo não invertido) descreve os principais processos da organização e faz referência à estrutura organizacional e à cadeia de valor do BCB.

Com base no modelo, foi desenvolvida uma rede semântica na forma de um mapa conceitual para evidenciar a relação entre os principais conceitos de governança e de gestão da organização. Esse mapa conceitual, que representa o modelo de governança e gestão do $B C B$, é descrito nas subseções a seguir utilizando-se as perspectivas de observação da governança externa e interna. Os componentes do modelo, por sua vez, estão organizados nos triângulos invertidos, que representam a governança e a gestão do $B C B$, e no elemento central, que faz o elo entre os agentes de governança e gestão, conforme mostra a Figura 2.

\section{Governança externa do BCB}

Esta perspectiva destaca as relações do BCB com as estruturas e os setores de diferentes esferas, com foco na formulação e na implementação das políticas, bem como o atendimento das demandas da sociedade. A Figura 3 evidencia os componentes do modelo que orientam as ações do BCB para o atendimento de suas funções e obrigações legais.

\footnotetext{
${ }^{4}$ Atual Ministério da Economia.
} 
Figura 3 | Direcionadores que norteiam as ações do BCB

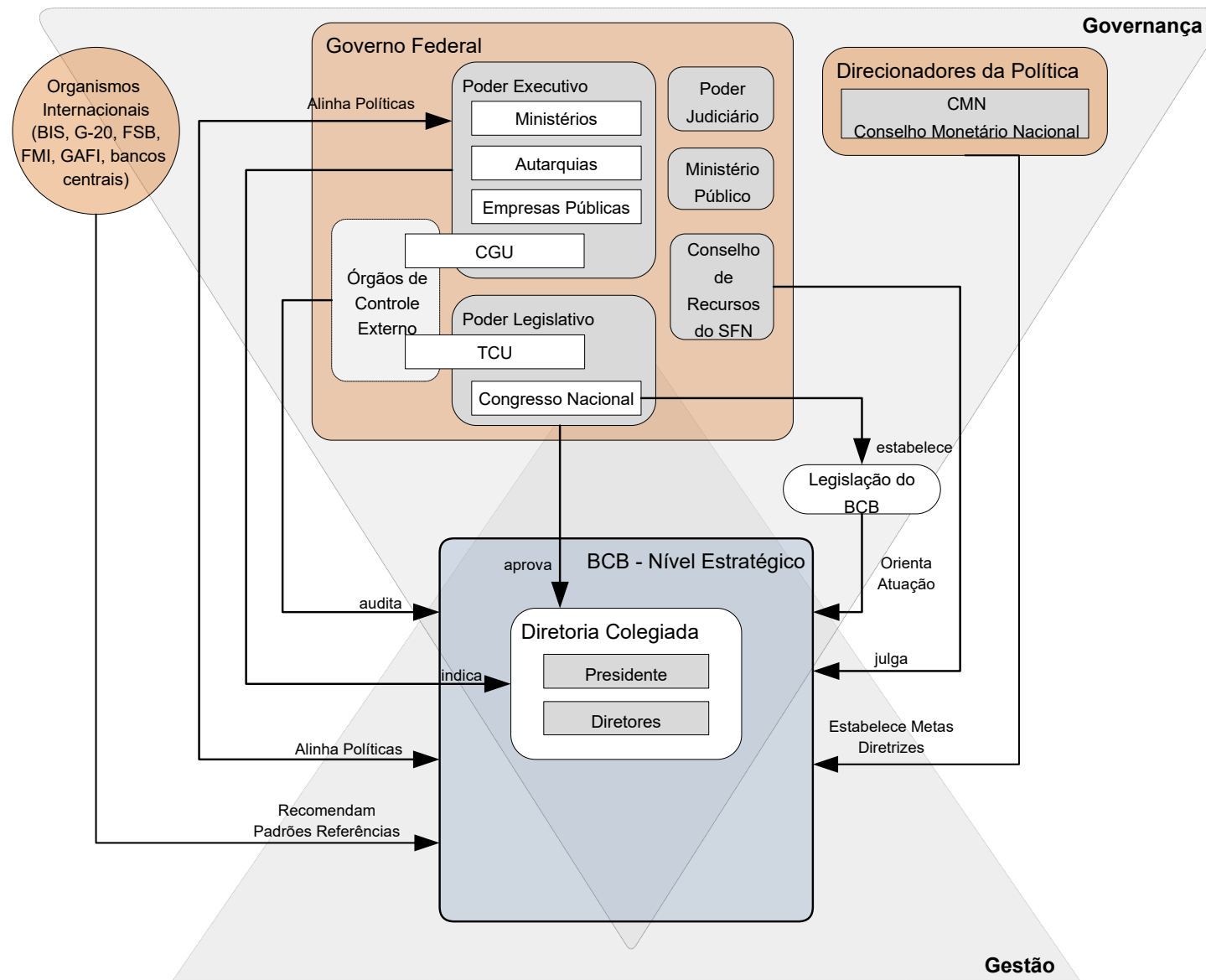

Fonte: elaboração própria.

Observa-se que as ações do BCB são consistentes com a execução da política econômico-financeira estipulada pelo Poder Executivo, ao qual está vinculado e subordinado. O Ministério da Economia formula e executa a política econômica brasileira e o CMN formula a política da moeda e do crédito, objetivando a estabilidade da moeda e o desenvolvimento econômico e social do país. Conforme o BCB (2016), o relacionamento entre o $\mathrm{BCB}$ e o Parlamento contempla respostas a pleitos formais e informais oriundos do Poder Legislativo, como os requerimentos de informação de autoria dos deputados e senadores. O CRSFN, órgão colegiado, de segundo grau, integrante da estrutura do Ministério da Economia, tem como competência julgar, em segunda e última instância, os 
recursos e interpostos das decisões relativas à aplicação de penalidades administrativas pelo BCB. Os órgãos de controle Tribunal de Contas da União (TCU), que exerce a fiscalização contábil, financeira, orçamentária, operacional e patrimonial, e a Controladoria-Geral da União (CGU), responsável pela função correcional e pela prevenção e combate à corrupção, executam ações de auditoria no BCB.

No grupo dos atores externos, há organismos que atuam em nível internacional e emitem recomendações relevantes na área de atuação do BCB. Essas recomendações podem influenciar o aprimoramento dos instrumentos de regulação e de supervisão empregados pela instituição, bem como das práticas de governança corporativa (BCB, 2016).

A Figura 4 apresenta a relação do BCB com a sociedade, que é componente essencial da sua governança para o alcance sustentável das metas da instituição. O envolvimento da sociedade é alcançado mediante a prática contínua dos princípios de governança, principalmente os princípios da transparência e da prestação de contas (BCB, 2016). 
Figura 4 | A relação do BCB com a sociedade

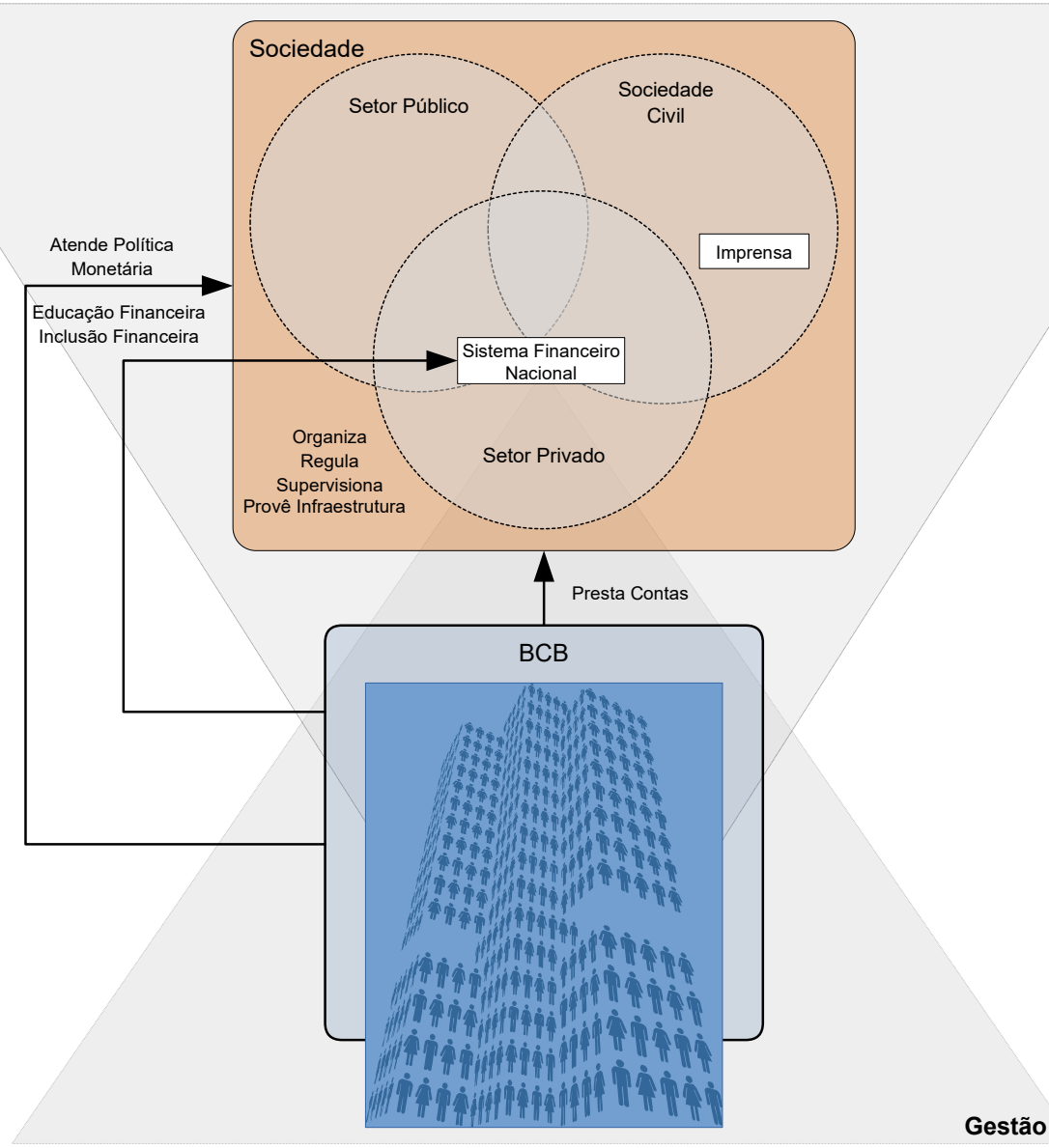

Governança

Fonte: elaboração própria.

O BCB relaciona-se diretamente com o cidadão, prestando informações sobre diversos assuntos de seu interesse. São informações sobre as regras de funcionamento do Sistema Financeiro Nacional e de seus agentes e sobre as atividades e produtos da própria instituição, que envolvem cadastros e sistemas de informação mantidos pelo BCB, meio circulante, indicadores econômicos e financeiros, câmbio e capitais internacionais (BCB, 2016). No âmbito da sociedade, cabe destacar o Sistema Financeiro Nacional (SFN) como um grande interessado nas ações do BCB. Neste caso, leva-se em consideração o interesse coletivo do SFN, de forma a preservar sua existência e sua funcionalidade (BCB, 2016). 


\section{Governança interna do BCB}

Esta dimensão do modelo, representada na Figura 5, expõe como os recursos da organização são dirigidos, controlados e avaliados. É o principal componente do sistema de governança do BCB. O Presidente e os Diretores formam a Diretoria Colegiada, órgão colegiado responsável pelo direcionamento estratégico do BCB. Seu papel é ser o elo entre os agentes de governança (governança externa) e a gestão da organização. Dentre as competências da Diretoria Colegiada, destacam-se (BCB, 2016): (i) fixar, em reunião do Comitê de Política Monetária (Copom), a meta da Taxa Selic; (ii) definir e aprovar as orientações e diretrizes estratégicas para a atuação do Banco Central; (iii) formular, acompanhar e controlar as diretrizes estabelecidas pelo Conselho Monetário Nacional (CMN). 
Figura 5 | 0 elo entre a governança e a gestão do BCB

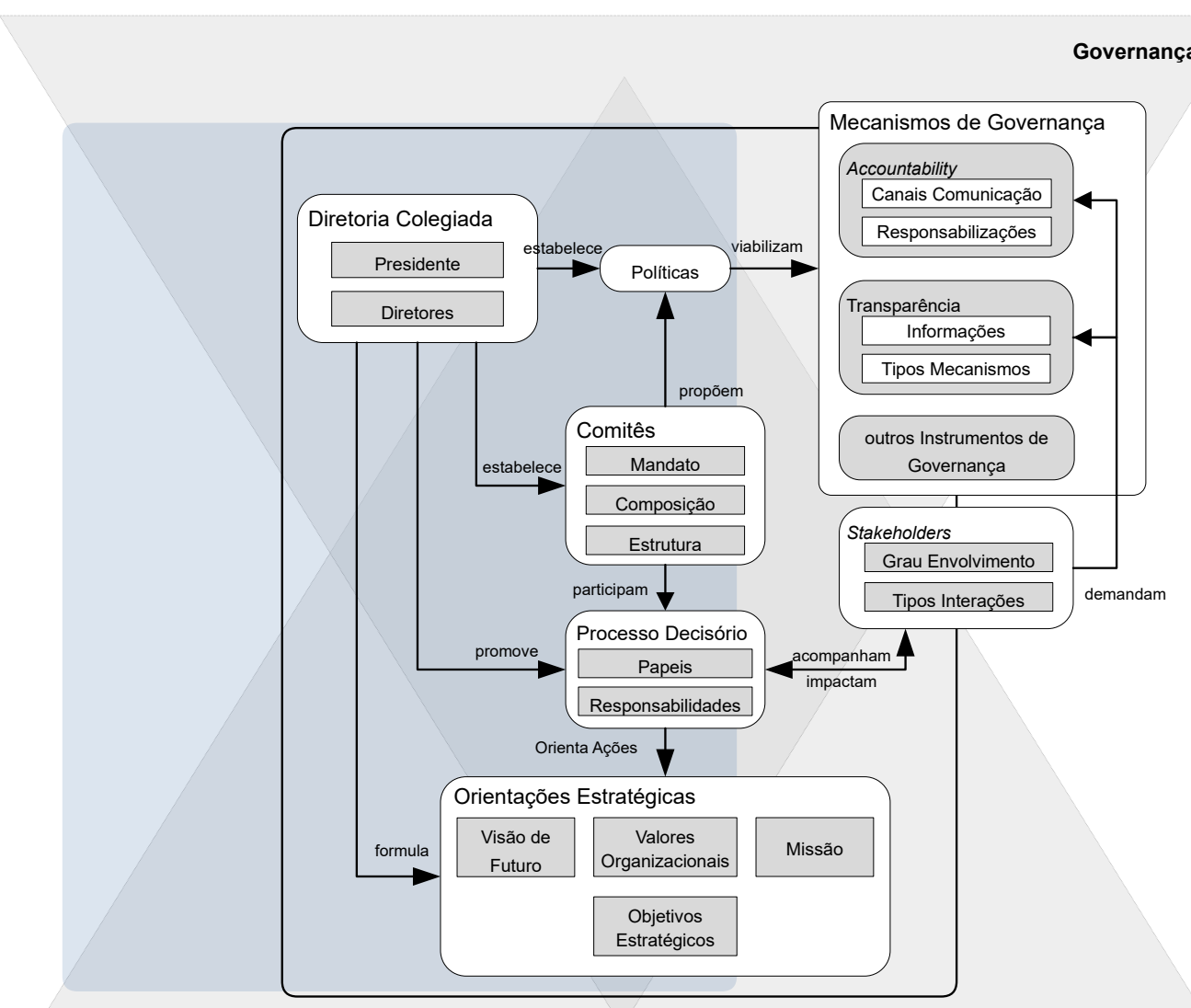

Gestão

Fonte: elaboração própria.

A auditoria interna, ouvidoria, corregedoria, procuradoria-geral e secretariaexecutiva desempenham papel fundamental na governança do $\mathrm{BCB}$, assegurando o controle interno da instituição, o canal de comunicação com a população, a prevenção e a apuração de irregularidades atribuídas a servidores, a assessoria jurídica e representação no exercício do procuratório judicial e extrajudicial, respectivamente. Por sua vez, os comitês são órgãos colegiados que auxiliam a alta administração no processo decisório, com o aproveitamento de experiências diferenciadas. 
A estrutura e funcionamento dos comitês se encontram em normativos específicos. Cabe destacar os comitês de políticas: (i) Comitê de Política Monetária (Copom), com a atribuição de executar a política monetária; e (ii) o Comitê de Estabilidade Financeira (Comef), com o objetivo de avaliar a estabilidade financeira e definir as diretrizes e as estratégias do BCB para a mitigação do risco sistêmico no Sistema Financeiro Nacional; e os comitês de gestão: (i) Comitê Estratégico de Gestão Pessoas (CGP), com a finalidade de desenvolver a gestão de pessoas do BCB; (ii) Comitê de Governança de Informações (CGI), com o propósito de implementar a Política de Governança da Informação do BCB, possibilitando o aumento de eficiência na gestão de dados e minimizando os riscos operacionais; (iii) Comitê de Projetos Corporativos (CPC), com a responsabilidade de apreciar as proposições de projetos corporativos e propor a priorização e o balanceamento dos projetos; (iv) Comitê Executivo do Plano Diretor de Tecnologia da Informação (PDTI), com a finalidade de deliberar sobre a transposição de recursos financeiros de Tecnologia da Informação e Comunicação (TIC); e (v) a Comissão de Ética, que promove a adoção e a aplicação das normas do Código de Ética Profissional do Servidor Público Civil do Poder Executivo federal e do Código de Conduta dos servidores do Banco Central.

Esta perspectiva do modelo também evidencia os mecanismos de governança que promovem o apoio do público e fortalecem a credibilidade necessária para a condução da política monetária e a política de estabilidade financeira. As práticas de accountability ajudam a legitimar a autonomia do Banco Central, angariando o apoio do público e das partes interessadas para a sua autonomia e fortalecimento de sua credibilidade. A transparência procura garantir que as ações do BCB sejam facilmente detectadas, suas políticas sejam de fácil compreensão e seus pronunciamentos sejam isentos de erros ou enganos. A experiência internacional mostra que a transparência, processos de tomada de decisão em grupo e políticas de comunicação são, atualmente, áreas de maior preocupação nos bancos centrais.

Um aspecto importante de conexão entre a governança e a gestão do BCB é o processo de planejamento estratégico. A Figura 6, que apresenta o ciclo de gestão do BCB, é utilizada para a compreensão desse processo (BCB, 2016). O planejamento estratégico tem o objetivo de estabelecer um foco para a atuação da instituição e orientar as ações para o atendimento das suas funções e obrigações legais. Tem como referência os desafios identificados, as mudanças ocorridas nos ambientes interno e externo e as orientações emanadas da alta administração. 
O processo se inicia com a revisão das orientações estratégicas (missão institucional, visão de futuro, valores organizacionais, objetivos estratégicos). A lógica do plano estratégico pauta-se nos objetivos e direcionamentos estratégicos definidos corporativamente, os quais orientam as áreas e unidades do banco no planejamento das suas ações (projetos, iniciativas e atividades de relevância estratégica). Essas ações impactam e moldam os processos de trabalho que são gerenciados sob a perspectiva de uma cadeia de valor. Os resultados são monitorados e subsidiam ações para a priorização da utilização dos recursos disponíveis, bem como promovem aprimoramentos nas práticas de gestão de pessoas e induzem mudanças na cultura organizacional. As equipes pautam-se nas atribuições definidas no regimento interno, nos limites de apetite ao risco e no orçamento disponível para a realização das ações e execução dos processos de trabalho (BCB, 2016). 
Figura 6 | Ciclo da gestão do BCB
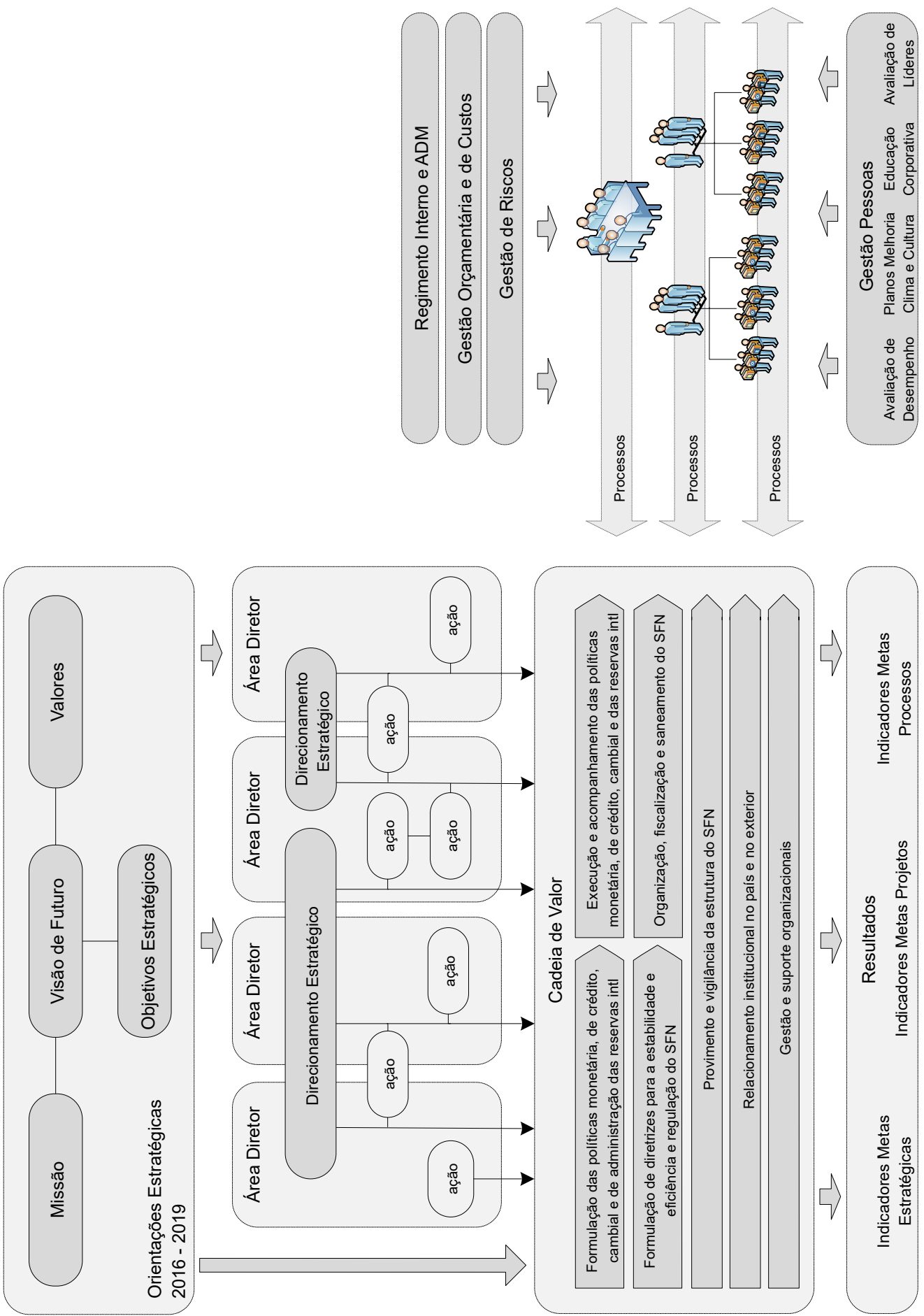

Fonte: BCB (2016, p. 34). 
Durante um ciclo de execução do planejamento estratégico, novas ações podem surgir. A Diretoria Colegiada revisa periodicamente a agenda de trabalho do $B C B$, garantindo a dinâmica e a avaliação contínua da estratégia, até o estabelecimento de um novo ciclo de planejamento estratégico. Os componentes do ciclo de gestão da Figura 6 estão detalhados no modelo de governança e gestão do BCB nas Figuras a seguir.

A Figura 7 mostra o papel do Comitê de Projetos Corporativos (CPC) no direcionamento dos projetos corporativos para o alcance dos objetivos estratégicos do BCB. Os processos de trabalho estão organizados de forma a atender a missão institucional e a estrutura hierárquica das atividades é representada na visão de uma cadeia de valor.

Figura 7 | Os projetos corporativos e a cadeia de valor

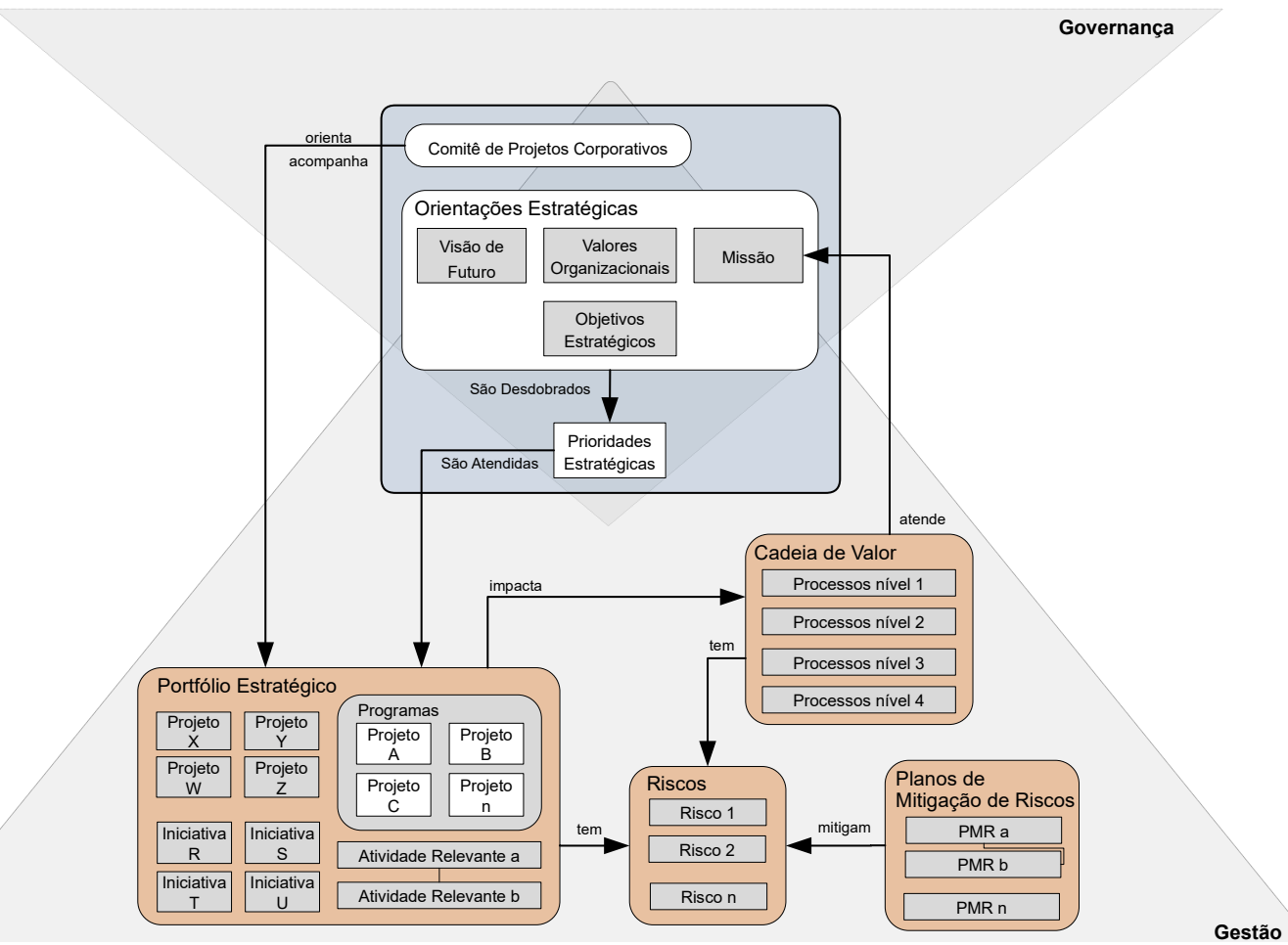

Fonte: elaboração própria.

A cadeia de valor do BCB relaciona de forma lógica todos os processos, proporcionando maior clareza para a avaliação de oportunidades de melhoria dos 
processos e produtos entregues à sociedade. Além disso, a cadeia de valor está se tornando base comum de conexão entre diferentes domínios de gestão do BCB, como: gestão de riscos corporativos; gestão do programa de capacitação; gestão de conteúdo para a comunicação organizacional; e governança da informação.

O Comitê de Gestão de Pessoas (CGP), apresentado na Figura 8, contribui para a articulação e envolvimento das áreas do BCB nas discussões relacionadas às políticas de recursos humanos. O principal objetivo é a integração da gestão de pessoas com os outros processos de gestão do BCB. Todos os servidores podem participar enviando sugestões e críticas. O CGP define diretrizes para temas relacionados à avaliação de desempenho individual, gestão do clima organizacional, sucessão, processo de mobilidade de servidores e concurso público, dentre outros.

Figura 8 | A gestão de pessoas

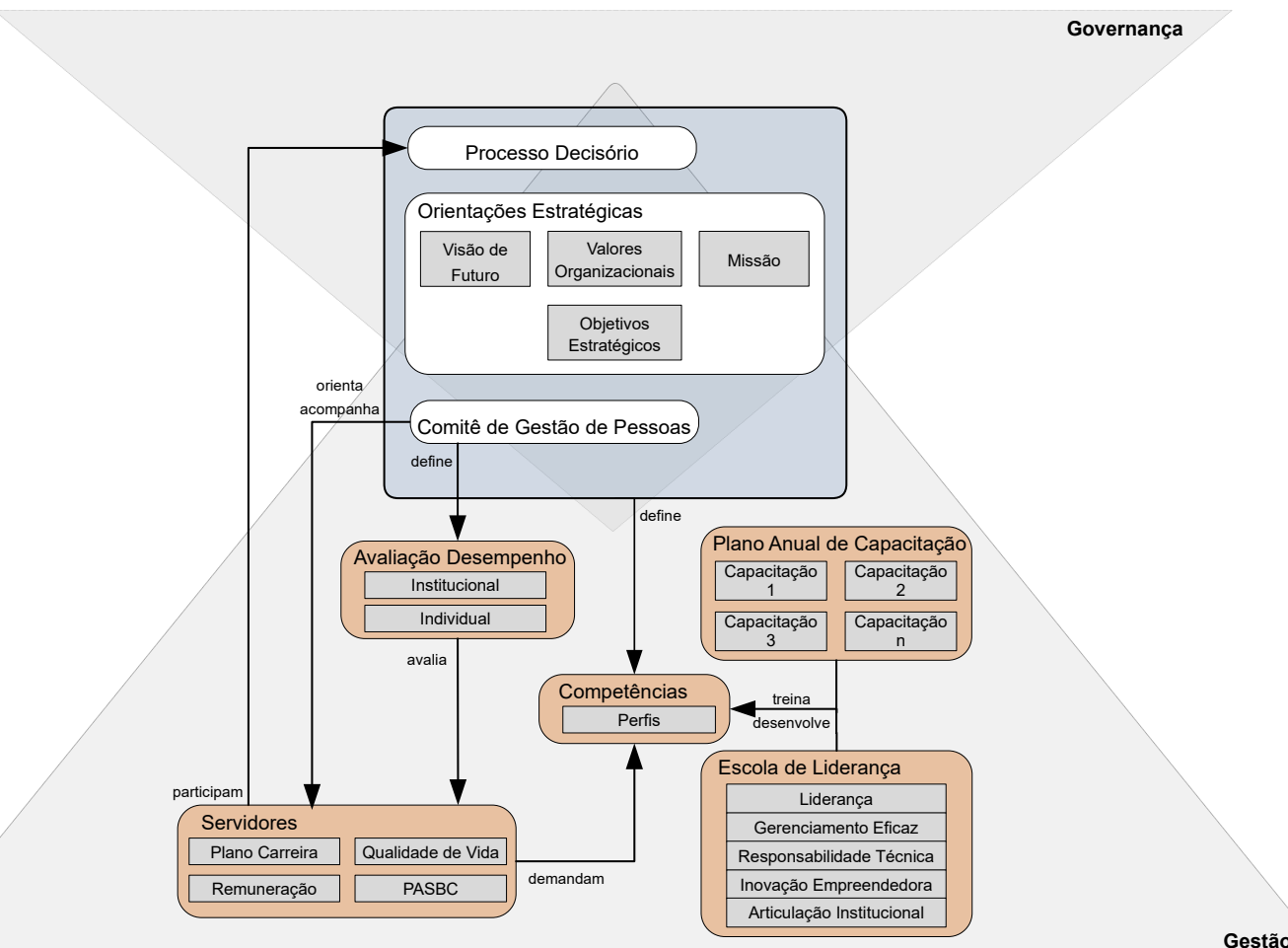

Fonte: elaboração própria. 
O Plano Anual de Capacitação e a Escola de Lideranças são programas de desenvolvimento profissional permanente e continuado dos servidores do $B C B$, por meio do alinhamento de competências. Contemplam ações educacionais, de curto prazo, promovidas pelo BCB (turmas fechadas) ou oferecidas pelo mercado (turmas abertas). A Escola de Lideranças visa formar gerentes de acordo com o perfil de liderança definido pelo BCB. O perfil de liderança é uma síntese profissional sobre o que se espera, em termos de competências, de um gestor.

Dentre as iniciativas de governança com foco na gestão, também se destacam a gestão da cultura e do clima organizacional, representados na Figura 9.

Figura 9 | Gestão da cultura e do clima organizacional

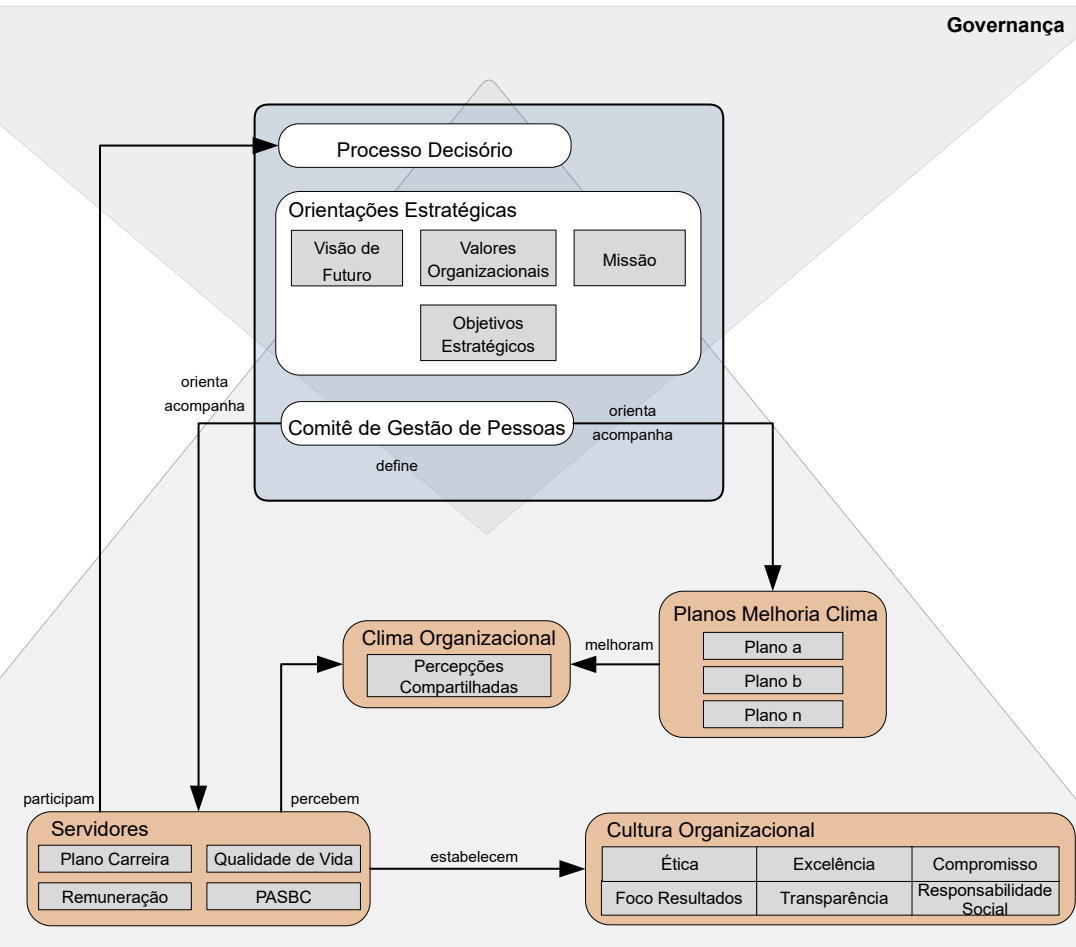

Gestão

Fonte: elaboração própria.

A gestão da cultura promove os valores organizacionais do órgão, como a Semana da Cultura Organizacional, evento anual de reflexão da prática dos valores e de formas de 
fortalecimento. As pesquisas de clima organizacional e de líderes também fazem parte da agenda do $\mathrm{BCB}$. Os resultados da pesquisa de clima permitem verificar a percepção dos servidores sobre as políticas, práticas e os procedimentos de gestão organizacional, e desenvolver ações que impactem positivamente a motivação, a satisfação e o desempenho do trabalho. A avaliação de líderes proporciona uma visão da atuação das lideranças, fornecendo feedback aos gestores sobre a sua gestão e promovendo o desenvolvimento organizacional.

\section{Considerações finais}

O objetivo principal deste trabalho é promover a compreensão de boas práticas de governança corporativa e de gestão nas organizações públicas e, consequentemente, a sua adoção. Para facilitar o entendimento do processo decisório e a interdependência entre as diferentes áreas, assim como a relação das principais partes interessadas, foi apresentado o modelo de governança e gestão do BCB. Os resultados da análise do modelo possibilitam observar: (i) a estrutura de governança; (ii) os direcionadores que norteiam as ações da organização; (iii) a relação com o ambiente externo; (iv) a relação entre os processos de governança corporativa e de gestão, com destaque ao desdobramento do planejamento estratégico nos níveis táticos e operacionais e o papel dos comitês de políticas e de gestão como principais elementos de conexão; (v) o ciclo de gestão; (vi) o direcionamento dos projetos corporativos e o papel da cadeia de valor; (vii) os processos de gestão de pessoas, cultura e do clima organizacional.

O modelo utiliza redes semânticas na forma de um mapa mental. Isso permitiu aos participantes das oficinas específicas a representação intuitiva do modelo, na forma de conceitos e seus relacionamentos. Cabe destacar que são escassos na literatura nacional a explicitação de um modelo detalhado de alinhamento de governança corporativa e gestão. Desse modo, este estudo preenche essa lacuna de pesquisa, contribuindo com o método para a descrição e análise da relação entre governança e gestão e com o desenvolvimento de novas abordagens e pesquisas nessa área, considerando sobretudo a especificidade das organizações da administração indireta - como é o caso do BCB. 
Em termos de limitações do estudo, ressalta-se que a visualização das redes semânticas, apesar das vantagens do seu uso para explicitar associações entre conceitos, pode gerar inferências incorretas. Ou seja, neste trabalho, a compreensão das estruturas das redes depende de descrições apuradas sobre as relações entre os seus elementos, sendo que nem todas as associações foram devidamente exploradas. Ainda, o trabalho não realiza uma análise crítica do modelo, como a relação do seu conteúdo com os fatores de estrutura de governança para bancos centrais verificados na literatura (Figura 1).

No caso do BCB, destaca-se que o modelo apresentado neste estudo foi desenvolvido durante o ciclo do planejamento estratégico 2010-2015 e empregado para descrever e comunicar os seus processos de governança e gestão no órgão. A representação dos instrumentos de gestão permitiu demonstrar a importância do relacionamento dos diferentes departamentos que administram os diversos instrumentos de gestão existentes. O ciclo de gestão (Figura 6), por exemplo, foi empregado para facilitar a compreensão do desdobramento da estratégia e a sua relação com os principais processos de gestão, principalmente aqueles tratados por diferentes unidades organizacionais. Além disso, o modelo auxiliou o BCB nas apresentações dos seus processos de governança e gestão a outros órgãos, nacionais e internacionais. Com base nessa experiência, entende-se que a descrição do modelo na forma de redes semânticas pode ajudar outras organizações, em especial do setor público, na reflexão sobre suas regras e práticas de governança corporativa e de gestão para o seu aprimoramento.

Para trabalhos futuros, sugere-se avaliar o potencial efetivo do uso de redes semânticas para a evidenciação e promoção de boas práticas de governança corporativa e de gestão nas organizações, e de que forma a construção dessas estruturas pode ser aprimorada para facilitar a comunicação e o envolvimento dos servidores na adoção das referidas práticas. Além disso, propõe-se aos pesquisadores da área de governança corporativa o desenvolvimento de uma ontologia com a definição de um vocabulário comum que facilite a intepretação das informações e promova o seu compartilhamento entre os servidores, partes interessadas e sistemas computacionais (interoperabilidade semântica). 


\section{Referências bibliográficas}

ADAMS, W.A. A transdisciplinary ontology of innovation governance. Artificial Intelligence and Law, v. 16, n. 2, 147-174 p., 2008.

ALBERT, D.; STEINER, C.M. Representing domain knowledge by concept maps: how to validate them? In: Окамото, T.; Albert, D.; HondA, T.; HesSE, F.W. (eds.), The 2nd Joint Workshop of Cognition and Learning through Media-Communication for Advanced E-Learning, Tokyo, 2005, 169-174 p. Disponível em: <http://telearn.archives-ouvertes.fr/docs/00/19/04/01/PDF/AlbertDietrich-2005.pdf>. Acesso em: 11 ago. 2014.

AMTENBRINK, F. The three pillars of central bank - towards a model central bank law or a code of good governance? International Monetary Fund, v. 4, 2005, 101-132 p. Disponível em: <http:// ssrn.com/abstract=1138195>. Acesso em: 18 fev. 2014.

Banco Central do BRAsil (BCB). Relatório de gestão - 2016. Brasília, DF, 2016. Disponível em: <http://www.bcb.gov.br/pre/audit/relgest/Relatorio_de_Gestao_BC_2016.pdf>. Acesso em: 04 ago. 2017.

BERGER, H.; NITSCH, V.; LYBEK, T. Central bank boards around the world: why does membership size differ? IMF Working Paper WP/06/281, International Monetary Fund (IMF), Monetary and Capital Markets Department, 2006. Disponível em: <https://www.imf.org/external/pubs/ft/wp/2006/ wp06281.pdf>. Acesso em: 19 dez. 2013.

BANK FOR INTERNATIONAL SETTLEMENTS (BIS). Issues in the governance of central banks. A report from the Central Bank Governance Group, 2009. Disponível em: <http://www.bis.org/publ/ othp04.pdf>. Acesso em: 19 dez. 2013.

Blumberg, B.; CoOPeR, D. R.; SCHIndler, P. S. Business Research Methods, McGraw-Hill Education, Maidenhead, p. 278-298, 2005.

BORST, W.N. Construction of engineering ontologies for knowledge sharing and reuse. Tese (doutorado) - Universiteit Twente, Enschede, 1997.

BRANDAS, C. Formal representation of corporate governance principles and codes. Procedia Social and Behavioral Sciences, v. 73, p. 744-750, 2012.

BRANDIS, K.; DZOMBETA, S.; HAUFE, K. Towards a framework for governance architecture management in cloud environments: a semantic perspective. Future Generation Computer Systems, v. 32, , p. 274-281, 2014.

BRASIL. Banco Central do Brasil. Funções do Banco Central do Brasil. Série Perguntas mais Frequentes. Departamento de Relacionamento com Investidores e Estudos Especiais (Gerin). Brasília, DF: Bacen, 2016.

CADBURY. Cadbury Committee. Report of the committee on the financial aspects of corporate governance. Londres: Great Britain by Burgess Science Press, 1992. Disponível em: <http://www. ecgi.org/codes/documents/cadbury.pdf>. Acesso em: 25 mar. 2015. 
CANÃs, A.J.; NovaK, Joseph D. What is a concept map? Institute for Human and Machine Cognition, 2009. Disponível em: <http://cmap.ihmc.us/docs/conceptmap.html>. Acesso em: 11 ago. 2014.

CAVAlCANTE, P.; PIRES, R. Governança pública: construção de capacidades para a efetividade da ação governamental. Nota técnica n. 24. Brasília: Ipea, 2018. Disponível em: <http://repositorio. ipea.gov.br/handle/11058/8581>. Acesso em: 3 nov. 2018.

CHOU, C.; CHI, Y.; TZENG, J. A research on how to construct prototype of knowledge ontology based on glossary -- Using the domain knowledge of "corporate governance" as an illustration. Journal of Library and Information Science Research, v. 6, n. 2, p. 37-81, 2012.

CiLliers, P. What can we learn from a theory of complexity? Emergence, v.2 , n. 1, p. 23-33, 2000.

Crowe, C.; MeAde, E.E. The evolution of central bank governance around the world. Journal of Economic Perspectives, v. 21, n. 4, p. 69-90, 2007.

DELOITTE. Deloitte Development LLC. Developing an effective governance operating model: a guide for financial services boards and management teams, 2013. Disponível em: <http://www2. deloitte.com/content/dam/Deloitte/global/Documents/Financial-Services/dttl-fsi-US-FSI-Developi nganeffectivegovernance-031913.pdf>. Acesso em: 25 mar. 2015.

DUARTE, J.C. Uma arquitetura ágil da informação. Tese (doutorado) - Universidade de Brasília, Brasília, 2011.

European Central Bank (ECB). The accountability of the ECB. Monthly Bulletin, nov. 2002. Disponível em: <https://www.ecb.europa.eu/pub/pdf/other/pp45_57_mb200211en.pdf>. Acesso em: 29 jan. 2014.

EIJfFINGER, S.C.W.; GERAATS, P.M. How transparent are central banks? European Journal of Political Economy, v. 22, n. 1,p. 1-21., 2006.

FARIA, F.A.; STREIT, R.E. Governança em bancos centrais: um estudo comparativo das práticas de governança dos bancos centrais do Brasil, Canadá e Inglaterra. Revista de Administração Pública, v. 50, n. 5, , p. 765-794, 2016.

GIL, A.C. Métodos e técnicas de pesquisa social. 6. ed. São Paulo: Atlas, 2008. 200 p.

GRUBER, T.R. Toward principles for the design of ontologies used for knowledge sharing. International Journal of Human-Computer Studies, v. 34, n. 5-6 , p. 907-928, 1995.

GUARINO, N. Understanding, building and using ontologies. International Journal of HumanComputer Studies, v. 46, n. 2-3, , p. 293-310, 1997.

GUNS, R. Tracing the origins of the semantic web. Journal of the American Society for Information Science and Technology, v. 64, n. 10, , p. 2173-2181, 2013.

Haidegger, T.; BarReto, M.; Gonçalves, P.; Habib, M.K.; Ragavan, S.K.V.; LI, H.; VAcCARella, A.; Perrone, R.; Prestes, E. Applied ontologies and standards for service robots. Robotics and Autonomous Systems, v. 61 , p. 1215-1223, 2013. 
HARTLEY, R.T.; BARNDEN, J.A. Semantic networks: visualizations of knowledge. Trends in Cognitive Sciences, v. 1, n. 5 , p. 169-175, 1997.

HILBERS, P.; DALTON, J. The role of internal control and audit systems in supporting central bank governance and transparency. MAE Operational Paper OP/99/1, IMF - International Monetary Fund, Monetary and Exchange Affairs Department. Jul., 1999.

InStituto BRAsileiro de Governança Corporativa (IBGC). Código das melhores práticas de governança corporativa. 4a ed. São Paulo: IBGC, 2009. 73 p. Disponível em: <http://www.ibgc.org. br/userfiles/files/Codigo_Final_4a_Edicao.pdf>. Acesso em: 07 ago. 2014.

KHAN, A. Central bank governance and the role of nonfinancial risk management. IMF Working Paper WP/16/34, International Monetary Fund (IMF), Monetary and Capital Markets Department, 2016. Disponível em: <https://www.imf.org/external/pubs/ft/wp/2016/wp1634.pdf >. Acesso em: 26 fev. 2016.

$\mathrm{KOCH}$, E.B. Challenges for governance at central banks. In: $\mathrm{KoCH}$, E.B. Challenges at the Bank for International Settlements, Basel, Switzerland: Springer Berlin Heidelberg, 2007. p. 9-29.

KoetTer, M.; RoszBACH, K.; SPAgnolo, G. Financial stability and central bank governance. Social Science Research Network, 2012. Disponível em: <http://dx.doi.org/10.2139/ssrn.2334224>. Acesso em: 30 mar. 2015.

Lehmann, F. Semantic networks. Computer \& Mathematics with Applications, v. 23, n. 2-5 , p. 1-50, 1992.

LYBEK, T.; MORRIS, J. Central bank governance: a survey of boards and management. IMF Working Paper WP/04/226, International Monetary Fund (IMF), Monetary and Financial Systems Markets Department, 2004. Disponível em: <http://www.imf.org/external/pubs/ft/wp/2004/wp04226. pdf>. Acesso em: 18 fev. 2014.

LYNN, L.E., Jr.; HEINRICH, C.J.; HILL, C. Improving governance: a new logic for empirical research. Washington, DC: Georgetown University Press, 2001.

LYNN, L.E., Jr. Public management and government performance: a consideration of theory and evidence. Working Paper Series: 97.4. The Harris School, The University of Chicago, 1997.

MARCINKOWSKA, M. Corporate governance in banks: problems and remedies. Financial Assets and Investing, v. 3, n. 2 p. 47-67, 2012.

Medina NiEto, M.A. An overview of ontologies. Technical Report. Center for Research in Information and Automation Technologies, Interactive and Cooperative Technologies Lab, Universidad de las Américas Puebla, Mexico, 2003.

MendzelA, J. Improving institutional governance in central banks. Central Banking Journal, Sep. 2009. Disponível em: <http://www.mendhurst.com/download/improving-institutionalgovernance-in-central-banks.pdf>. Acesso em: 19 dez. 2013.

Moreira, E.S.; MARTimiano, L.A.F.; BRANDÃo, A.J.S.; BernaRdes, M.C. Ontologies for information security management and governance. Information Management \& Computer Security, v. 16, n. 2, p. 150-165, 2008. 
NoY, N.F.; McGuINESS, D.L. Ontology development: a guide to creating your first ontology. Stanford Knowledge Systems Laboratory: Technical Report KSL-01-05, Stanford Medical Informatics Technical Report SMI-2001-0880, 2001.

ORITANI, Yoshiharu. Public governance of Central Banks: an approach from new institutional economics. BIS Working Papers, n. 299, Bank for International Settlements, p. 1-44, 2010.

OffE, C. Governance: an "empty signifier"? Constellations, v. 16, n. 4 , p. 550-562, 2009.

PETERSON, R. Crafting information technology governance. Information Systems Management, Fall. 2004.

ROth, A.L.; WegneR, D.; ANTUNES JÚNIOR, J.A.V.; PADULA, A.D. Diferenças e inter-relações dos conceitos de governança e gestão de redes horizontais de empresas: contribuições para o campo de estudos. Revista de Administração, v. 47, n. 1 , p. 112-123, 2012.

SALEM, A.M.; ALfONSE, M. Ontology versus semantic networks for medical knowledge representation. In: WSEAS INTERNATIONAL CONFERENCE ON COMPUTERS, 12, 2008, Greece. Proceedings ... Heraklion, Crete Island, Greece, 2008. 769-774 p.

SAmPieRI, R.H.; Collado, C.F.; Luclo, P.B. Metodologia de pesquisa. 3a. ed. São Paulo: McGraw-Hill, 583 p., 2006.

SCHIFFMAN, H. Good governance for central banks. 2004. Disponível em: <http://www. centralbanking.com/central-banking-journal/feature/2070047/governance-central-banks>. Acesso em 24 dez. 2013.

SIBERT, A. Central banking by committee. DNB Working Paper, 2006. Disponível em: <http://www. dnb.nl/binaries/Working\%20Paper\%20No\%2091-2006_tcm46-146748.pdf>. Acesso em: 19 dez. 2013.

Souza Neto, J.; FerReira Neto, A.N. Metamodel of the IT governance framework Cobit. Journal of Information Systems and Technology Management, v. 10, n. 3 , p. 521-540, 2013.

SOWA, J.F. Semantic networks. In: SHAPIRO, S.C. (ed.). Encyclopedia of Artificial Intelligence. 2a ed. New York: Willey, 1992. Disponível em: <http://www.jfsowa.com/pubs/semnet.htm>. Acesso em: 22 jul. 2014.

TRIBUNAL DE CONTAS DA UNIÃO (TCU). Referencial básico de governança aplicável a órgãos e entidades da administração pública. 2a ed. Brasília: TCU, Secretaria de Planejamento, Governança e Gestão, 2014. Disponível em: <http://portal2.tcu.gov.br/portal/pls/portal/docs/2663788.PDF>. Acesso em: 25 mar. 2015.

VAN GRembergen, W.; HAES, S. Enterprise governance of information technology. New York: Springer, 2009.

WITHERELL, W. Corporate governance: a basic foundation for the global economy. Financial, Fiscal and Enterprise Affairs Directorate (DAF), Sep. 2000. Disponível em: <http://www.oecdobserver. org/news/fullstory.php/aid/317>. Acesso em: 29 mar. 2015. 
ZUBER-SKERRITT, O. Emancipatory Action Research for Organisational Change and Management Development, In: Zuber-Skerritt, O. (ed), 'New Directions in Action Research', Falmer Press, London, 1996, p. $83-104$.

\section{Agradecimentos:}

Os autores agradecem aos colegas do Departamento de Planejamento, Orçamento e Gestão (Depog) do Banco Central do Brasil pelas contribuições para o desenvolvimento do modelo.

\section{Rosalvo Ermes Streit}

(i) Orcid: https://orcid.org/0000-0003-4479-7966

Doutor em administração pela Universidade Federal do Rio Grande do Sul (UFRGS), servidor do Banco Central do Brasil e professor do Programa de Pós-Graduação Stricto Sensu em Governança, Tecnologia e Inovação da Universidade Católica de Brasília.

E-mail: rosalvo.streit@gmail.com

\section{Fernando de Abreu Faria}

(D) Orcid: https://orcid.org/0000-0003-4597-7475

Doutor em administração pela Universidade Federal do Rio Grande do Sul (UFRGS),

servidor do Banco Central do Brasil.

E-mail: fernando.afaria@outlook.com. 